International Journal of Soft Computing 7 (4): 146-156, 2012

ISSN: 1816-9503

(C) Medwell Journals, 2012

\title{
Generalized Projective Synchronization of Two-Scroll Systems via Adaptive Control
}

\author{
${ }^{1} \mathrm{P}$. Sarasu and ${ }^{2} \mathrm{~V}$. Sundarapandian \\ ${ }^{1}$ Faculty of Computer Science and Engineering, ${ }^{2}$ Research and Development Centre, \\ Vel Tech Dr. R.R. and Dr. S.R. Technical University Avadi, 600062 Chennai, India
}

\begin{abstract}
This study derives new results for the adaptive controller design for the Generalized Projective Synchronization (GPS) of identical Li 2-Scroll Chaotic Systems, identical Lu-Chen 2-Scroll Chaotic Systems and non-identical Li and Lu-Chen 2-Scroll Chaotic Systems. Lyapunov Stability Theory is the methodology used for establishing the adaptive GPS synchronization results derived in this study. Since, the Lyapunov exponents are not required for these calculations, the proposed Adaptive Control Method is very effective and convenient for achieving the Generalized Projective Synchronization (GPS) of the 2-Scroll Chaotic Systems. Numerical simulations are shown to demonstrate the effectiveness of the adaptive GPS synchronization results derived in this study for the 2-Scroll Chaotic Systems.
\end{abstract}

Key words: Adaptive control, chaos, Chaotic Systems, 2-Scroll Systems, generalized projective synchronization, Li System, Lu-Chen System

\section{INTRODUCTION}

Chaotic systems are non-linear dynamical systems which are characterized by sensitive dependence on initial conditions. This sensitivity is popularly known as the butterfly effect (Alligood et al., 1997). Chaos is an interesting non-linear phenomenon and has been studied well in the last three decades. Chaos Theory has wide applications in several fields like physical systems (Lakshmanan and Murali, 1996), chemical systems (Han et al., 1995) ecological systems (Blasius et al., 1999) secure communications (Cuomo and Oppenheim, 1993; Kocarev and Parlitz, 1995; Murali and Lakshmanan, 2003), etc. Chaos synchronization is a phenomenon that may occur when two or more chaotic oscillators are coupled or a chaotic oscillator drives another chaotic oscillator. Because of the butterfly effect which causes the exponential divergence of the trajectories of two identical Chaotic Systems started with nearly the same initial conditions, synchronizing two Chaotic Systems is seemingly a challenging research problem.

In most of the chaos synchronization approaches, the master-slave formalism is used. If a particular chaotic system is called the Master System and another Chaotic System is called the Slave System then the idea of the chaos synchronization is to use the output of the Master System to control the Slave System so that the output of the Slave System tracks the output of the Master System asymptotically. Since, the seminal research by Pecora and Carroll (1990) chaos synchronization problem has been studied well in the chaos literature.

In the last two decades, various schemes have been derived for chaos synchronization such as OGY Method (Ott et al., 1990), Active Control Method (Ho and Hung, 2002; Huang et al., 2004; Chen, 2005; Sundarapandian, 2011h), Adaptive Control Method (Lu et al., 2004; Chen and Lu, 2002; Sundarapandian, 2011a, e), TimeDelay Feedback Method (Park and Kwon, 2003), Backstepping Design Method (Wang and Ge, 2001; Xiau-Qun and Jun-An, 2003; Park, 2006; Vincent, 2007), Sampled-Data Feedback Synchronization Method (Lee et al., 2010), Sliding Mode Control Method (Slotine and Sastry, 1983; Utkin, 1993; Vaidyanathan and Sampath, 2011), etc. So far, many types of synchronization phenomenon have been presented such as complete synchronization (Pecora and Carroll, 1990), Generalized synchronization (Wang and Guan, 2006), Anti-synchronization (Zhang and Zhu, 2008; Chiang et al., 2008; Sundarapandian, 2011g), Hybrid synchronization (Sundarapandian, 2011b, c, d, f), Projective synchronization (Jia, 2007) and Generalized projective synchronization ( $\mathrm{Li}, 2009$; Sarasu and Sundarapandian 2011 a, b, 2012), etc.

Complete Synchronization (CS) is characterized by the equality of state variables evolving in time while Anti-Synchronization (AS) is characterized by the

Corresponding Author: P. Sarasu, Faculty of Computer Science and Engineering,

Vel Tech R.R. and S.R. Technical University Avadi, 600062 Chennai, India 
disappearance of the sum of relevant state variables evolving in time. In hybrid synchronization of two Chaotic Systems, one part of the systems is completely synchronized and the other part is anti-synchronized so that the Complete Synchronization (CS) and AntiSynchronization (AS) co-exist in the systems. Projective Synchronization (PS) is characterized by the fast that the Master and Slave Systems could be synchronized up to a scaling factor. In Generalized Projective Synchronization (GPS), the responses of the synchronized dynamical states synchronize up to a constant scaling matrix $\alpha$. It is easy to see that the complete synchronization and anti-synchronization are special cases of the generalized projective synchronization where the scaling matrix $\alpha=\mathrm{I}$ and $\alpha=-$ I, respectively.

This study describes the adaptive controller design for the GPS of the identical Li 2-Scroll Systems (Li et al., 2009) the identical Lu-Chen 2-Scroll Systems (Lu and Chen, 2002) and the non-identical Li and Lu-Chen 2-Scroll Systems. The adaptive GPS synchronization results for the 4-Scroll Systems have been established using the Lyapunov Stability Theory (Hahn, 1967).

\section{SYSTEMS DESCRIPTION}

In this study, researchers describe the 2-Scroll Chaotic Systems studied in this study. The Li 2-Scroll System (Li et al., 2009) is described by the 3D dynamics:

$$
\begin{aligned}
& \dot{\mathrm{x}}_{1}=\mathrm{a}\left(\mathrm{x}_{2}-\mathrm{x}_{1}\right) \\
& \dot{\mathrm{x}}_{2}=-\mathrm{x}_{2}+\mathrm{x}_{1} \mathrm{x}_{3} \\
& \dot{\mathrm{x}}_{3}=\mathrm{b}-\mathrm{cx}_{3}-\mathrm{x}_{1} \mathrm{x}_{2}
\end{aligned}
$$

Where:

$\mathrm{x}_{1}-\mathrm{x}_{3}=$ The states

$\mathrm{a}-\mathrm{c}=$ The constant, positive parameters of the system

The system (Eq. 1) exhibits a 2-scroll chaotic attractor when the system parameter values are chosen as:

$$
\mathrm{a}=5, \mathrm{~b}=16, \mathrm{c}=1
$$

The 2-scroll strange attractor of the Li System (Eq. 1) is shown in Fig. 1. The Lu-Chen 2-Scroll System (Lu and Chen, 2002) is described by the 3D dynamics:

$$
\begin{aligned}
& \dot{\mathrm{x}}_{1}=\mathrm{p}\left(\mathrm{x}_{2}-\mathrm{x}_{1}\right) \\
& \dot{\mathrm{x}}_{2}=\mathrm{rx}_{2}-\mathrm{x}_{1} \mathrm{x}_{3} \\
& \dot{\mathrm{x}}_{3}=-\mathrm{qx}_{3}+\mathrm{x}_{1} \mathrm{x}_{2}
\end{aligned}
$$

Where:

$\mathrm{x}_{1}-\mathrm{x}_{3}=$ The states

p-r $=$ Constant, positive parameters of the system

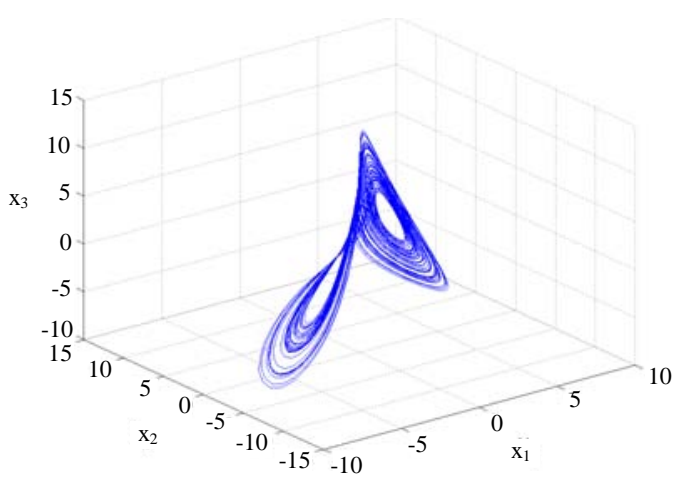

Fig. 1: The 2-scroll attractor of the Li System

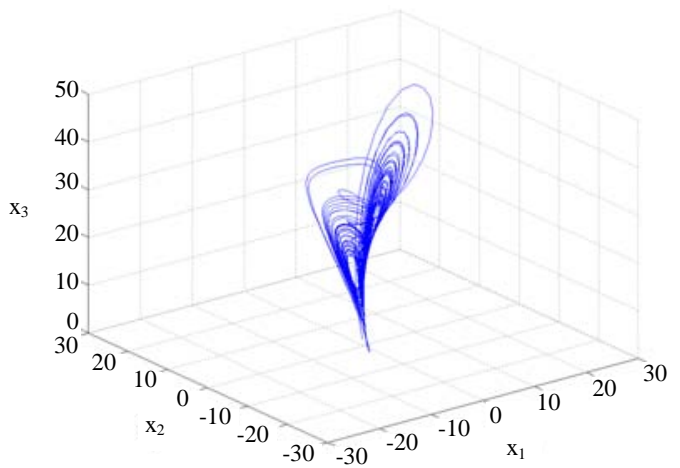

Fig. 2: The 2-scroll attractor of the Lu-Chen System

The system (Eq. 2) exhibits a 2-scroll chaotic attractor when the system parameter values are chosen as:

$$
\mathrm{p}=36, \mathrm{q}=3, \mathrm{r}=20
$$

The 2-scroll strange attractor of the Lu-Chen System (Eq. 2) is shown in Fig. 2.

\section{ADAPTIVE GENERALIZED PROJECTIVE SYNCHRONIZATION OF IDENTICAL LI 2-SCROLL SYSTEMS}

Theoretical results: In this study, researchers deploy adaptive control to derive results for the Generalized Projective Synchronization (GPS) of the identical Li 2-Scroll Systems (2009) when the system parameters are unknown. Thus, the Master System is described by the Li dynamics:

$$
\begin{aligned}
& \dot{x}_{1}=a\left(x_{2}-x_{1}\right) \\
& \dot{x}_{2}=-x_{2}+x_{1} x_{3} \\
& \dot{x}_{3}=b-c_{3}-x_{1} x_{2}
\end{aligned}
$$

Where:

$\mathrm{x}_{1}-\mathrm{x}_{3}=$ The states

$\mathrm{a}-\mathrm{c}=$ Unknown parameters of the system 
Also, the Slave System is described by the controlled Liu-Chen dynamics:

$$
\begin{aligned}
& \dot{y}_{1}=a\left(y_{2}-y_{1}\right)+u_{1} \\
& \dot{y}_{2}=-y_{2}+y_{1} y_{3}+u_{2} \\
& \dot{y}_{3}=b-c y_{3}-y_{1} y_{2}+u_{3}
\end{aligned}
$$

Where:

$\mathrm{y}_{1}-\mathrm{y}_{3}=$ The states

$\mathrm{u}_{1}-\mathrm{u}_{3}=$ The adaptive controls to be designed

The GPS synchronization errors are defined as:

$$
\mathrm{e}_{\mathrm{i}}=\mathrm{y}_{\mathrm{i}}-\alpha_{\mathrm{i}} \mathrm{x}_{\mathrm{i}},(\mathrm{i}=1,2,3)
$$

where, the scales $\alpha_{1}-\alpha_{3}$ are real numbers. The error dynamics is obtained as:

$$
\begin{aligned}
& \dot{e}_{1}=-a\left(e_{1}-y_{2}+\alpha_{1} x_{2}\right)+u_{1} \\
& \dot{e}_{2}=-e_{2}+y_{1} y_{3}-\alpha_{2} x_{1} x_{3}+u_{2} \\
& \dot{e}_{3}=b\left(1-\alpha_{3}\right)-c e_{3}-y_{1} y_{2}+\alpha_{3} x_{1} x_{2}+u_{3}
\end{aligned}
$$
by:

Researchers consider the adaptive controller defined

$$
\begin{aligned}
& \mathrm{u}_{1}=\hat{\mathrm{a}}\left(\mathrm{e}_{1}-\mathrm{y}_{2}+\alpha_{1} \mathrm{x}_{2}\right)-\mathrm{k}_{1} \mathrm{e}_{1} \\
& \mathrm{u}_{2}=\mathrm{e}_{2}-\mathrm{y}_{1} \mathrm{y}_{3}+\alpha_{2} \mathrm{x}_{1} \mathrm{x}_{3}-\mathrm{k}_{2} \mathrm{e}_{2} \\
& \mathrm{u}_{3}=\hat{\mathrm{b}}\left(1-\alpha_{3}\right)+\hat{c} \mathrm{e}_{3}+\mathrm{y}_{1} \mathrm{y}_{2}-\alpha_{3} \mathrm{x}_{1} \mathrm{x}_{2}-\mathrm{k}_{3} \mathrm{e}_{3}
\end{aligned}
$$

where, $\hat{a}-\hat{c}$ are estimates of the parameters $a-c$, respectively. Substituting Eq. 7 into Eq. 6, researchers obtain the closed-loop error dynamics:

$$
\begin{aligned}
& \dot{\mathrm{e}}_{1}=-(\mathrm{a}-\hat{\mathrm{a}})\left(\mathrm{e}_{1}-\mathrm{y}_{2}+\alpha_{1} \mathrm{x}_{2}\right)-\mathrm{k}_{1} \mathrm{e}_{1} \\
& \dot{\mathrm{e}}_{2}=-\mathrm{k}_{2} \mathrm{e}_{2} \\
& \dot{\mathrm{e}}_{3}=(\mathrm{b}-\hat{\mathrm{b}})\left(1-\alpha_{3}\right)-(\mathrm{c}-\hat{\mathrm{c}}) \mathrm{e}_{3}-\mathrm{k}_{3} \mathrm{e}_{3}
\end{aligned}
$$

Researchers define the parameter estimation errors as:

$$
e_{a}=a-\hat{a}, e_{b}=b-\hat{b}, e_{c}=c-\hat{c}
$$

Using Eq. 9, the error dynamics (8) is simplified as:

$$
\begin{aligned}
& \dot{e}_{1}=-e_{a}\left(e_{1}-y_{2}+\alpha_{1} x_{2}\right)-k_{1} e_{1} \\
& \dot{e}_{2}=-k_{2} e_{2} \\
& \dot{e}_{3}=(b-\hat{b})\left(1-\alpha_{3}\right)-(c-\hat{c}) e_{3}-k_{3} e_{3}
\end{aligned}
$$

For the derivation of the update law for adjusting the estimates of parameters, the Lyapunov Method is used. Researchers consider the quadratic Lyapunov function defined by:

$$
\mathrm{V}=\frac{1}{2}\left(\mathrm{e}_{1}^{2}+\mathrm{e}_{2}^{2}+\mathrm{e}_{3}^{2}+\mathrm{e}_{\mathrm{a}}^{2}+\mathrm{e}_{\mathrm{b}}^{2}+\mathrm{e}_{\mathrm{c}}^{2}\right)
$$
that:

Which is positive definite on $\mathrm{R}^{6}$. Researchers note

$$
\dot{\mathrm{e}}_{\mathrm{a}}=-\dot{\hat{\mathrm{a}}}, \dot{\mathrm{e}}_{\mathrm{b}}=-\dot{\hat{\mathrm{b}}}, \dot{\mathrm{e}}_{\mathrm{c}}=-\dot{\hat{\mathrm{c}}}
$$

Differentiating Eq. 11 along the trajectories of the system Eq. 10 and using Eq. 12, researchers find that:

$$
\begin{aligned}
\dot{\mathrm{V}}= & -\mathrm{k}_{1} \mathrm{e}_{1}^{2}-\mathrm{k}_{2} \mathrm{e}_{2}^{2}-\mathrm{k}_{3} \mathrm{e}_{3}^{2}+ \\
& \mathrm{e}_{\mathrm{a}}\left[-\mathrm{e}_{1}\left(\mathrm{e}_{1}-\mathrm{y}_{2}+\alpha_{1} \mathrm{x}_{2}\right)-\hat{\mathrm{a}}\right]+ \\
& \mathrm{e}_{\mathrm{b}}\left[\mathrm{e}_{3}\left(1-\alpha_{3}\right)-\dot{\hat{b}}\right]+\mathrm{e}_{\mathrm{c}}\left[-\mathrm{e}_{3}^{2}-\dot{\hat{\mathrm{c}}}\right]
\end{aligned}
$$

In view of Eq. 13 the estimated parameters are updated by the following law:

$$
\begin{aligned}
& \dot{\hat{\mathrm{a}}}=-\mathrm{e}_{1}\left(\mathrm{e}_{1}-\mathrm{y}_{2}+\alpha_{1} \mathrm{x}_{2}\right)+\mathrm{k}_{4} \mathrm{e}_{\mathrm{a}} \\
& \dot{\hat{\mathrm{b}}}=\mathrm{e}_{3}\left(1-\alpha_{3}\right)+\mathrm{k}_{5} \mathrm{e}_{\mathrm{b}} \\
& \dot{\hat{\mathrm{c}}}=-\mathrm{e}_{3}^{2}+\mathrm{k}_{6} \mathrm{e}_{\mathrm{c}}
\end{aligned}
$$

where the gains $\mathrm{k}_{4}-\mathrm{k}_{6}$ are positive constants.

Theorem 1: The adaptive control law (7) achieves General Projective Synchronization (GPS) between the identical Li 2-Scroll Chaotic Systems (3) and (4) where the parameter update law is given by Eq. 14 and the gains $k_{1}(i=1,2, \ldots, 6)$ are positive constants. The GPS errors $e_{1}(i=1,2,3)$ and the parameter estimation errors $\mathrm{e}_{\mathrm{a}}-\mathrm{e}_{\mathrm{c}}$ converge exponentially to zero as $\mathrm{t} \rightarrow \infty$ for all initial conditions.

Proof: Upon substituting the parameter update law (14) into the Eq. 13, researchers obtain the derivative of the quadratic Lyapunov function $\mathrm{V}$ as:

$$
\dot{\mathrm{V}}=-\mathrm{k}_{1} \mathrm{e}_{1}^{2}-\mathrm{k}_{2} \mathrm{e}_{2}^{2}-\mathrm{k}_{3} \mathrm{e}_{3}^{2}-\mathrm{k}_{4} \mathrm{e}_{\mathrm{a}}^{2}-\mathrm{k}_{5} \mathrm{e}_{\mathrm{b}}^{2}-\mathrm{k}_{6} \mathrm{e}_{\mathrm{c}}^{2}
$$

which is a negative definite function on $\mathrm{R}^{6}$. Hence, by Lyapunov Stability Theory (Hahn, 1967) it follows that the GPS errors $\mathrm{e}_{1} \rightarrow 0, \mathrm{e}_{2} \rightarrow 0, \mathrm{e}_{3} \rightarrow 0$ as $\mathrm{t} \rightarrow \infty$ and the parameter estimator error $\mathrm{e}_{\mathrm{a}} \rightarrow 0, \mathrm{e}_{\mathrm{b}} \rightarrow 0, \mathrm{e}_{\mathrm{c}} \rightarrow 0$ as $\mathrm{t} \rightarrow \infty$ for all initial conditions. This completes the proof.

Numerical results: For the numerical simulations, the fourth order Runge-Kutta Method is used to solve the two systems of differential Eq. 3 and 4 with the adaptive 

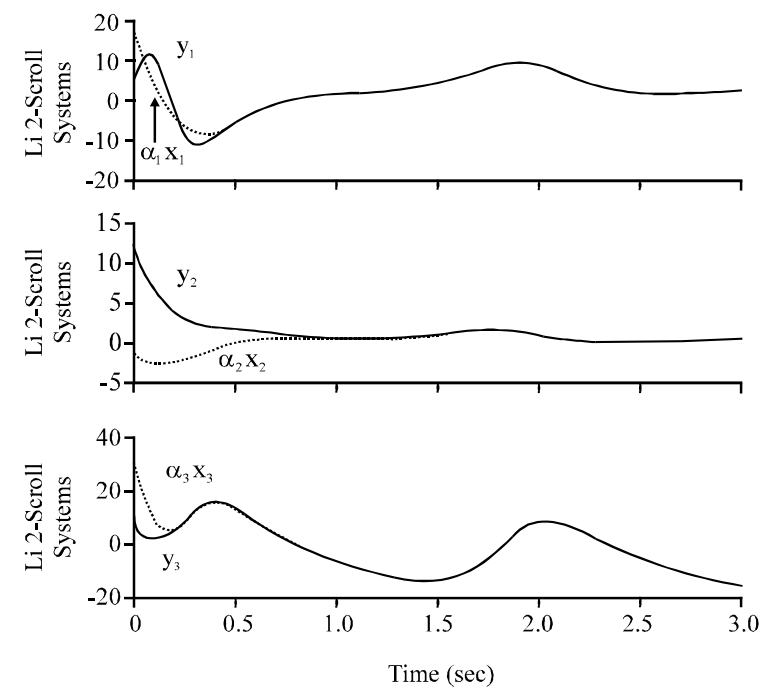

Fig. 3: GPS of the identical Li 2-Scroll Systems

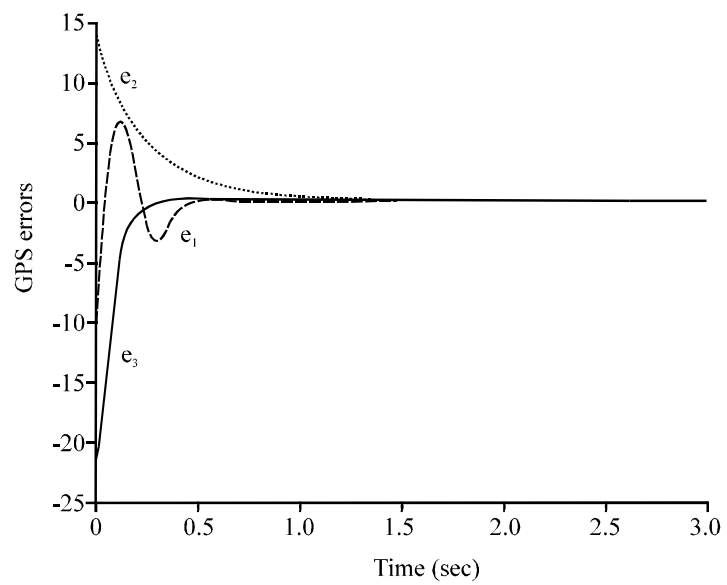

Fig. 4: Time history of the GPS errors

controller Eq. 7. The parameter estimates of the identical Li Systems 3 and 4 are taken so that the systems exhibit 2 -scroll chaotic attractors, i.e.:

$$
\mathrm{a}=5, \mathrm{~b}=16, \mathrm{c}=1
$$

Researchers take the state feedback gains as:

$$
k_{1}=4 \text { for } i=1,2, \ldots, 6
$$

The initial values of the parameter estimates are chosen as:

$$
\hat{a}(0)=4, \hat{b}(0)=18, \hat{c}(0)=9
$$

The initial values of the master system (3) are chosen as: 


\section{ADAPTIVE GENERALIZED PROJECTIVE SYNCHRONIZATION OF DENTICAL LU-CHEN 2-SCROLL CHAOTIC SYSTEMS}

Theoretical results: In this study, researchers deploy adaptive control to derive results for the Generalized Projective Synchronization (GPS) of the identical Lu-Chen 2-Scroll Systems (2002) when the system parameters are unknown. Thus, the master system is described by the Lu-Chen dynamics:

$$
\begin{aligned}
& \dot{x}_{1}=p\left(x_{2}-x_{1}\right) \\
& \dot{x}_{2}=\mathrm{rx}_{2}-x_{1} x_{3} \\
& \dot{x}_{3}=-\mathrm{qx}_{3}+\mathrm{x}_{1} \mathrm{x}_{2}
\end{aligned}
$$

Where:

$\mathrm{x}_{1}-\mathrm{x}_{3}=$ The states

$\mathrm{p}-\mathrm{r}=$ Unknown parameters of the system

Also, the slave system is described by the controlled Lu-Chen dynamics:

$$
\begin{aligned}
& \dot{y}_{1}=p\left(y_{2}-y_{1}\right)+u_{1} \\
& \dot{y}_{2}=r y_{2}-y_{1} y_{3}+u_{2} \\
& \dot{y}_{3}=-\mathrm{qy}_{3}+y_{1} y_{2}+u_{3}
\end{aligned}
$$

Where:

$\mathrm{y}_{1}-\mathrm{y}_{3}=$ The states

$\mathrm{u}_{1}-\mathrm{u}_{3}=$ The adaptive controls to be designed

The GPS synchronization errors are defined as:

$$
\mathrm{e}_{\mathrm{i}}=\mathrm{y}_{\mathrm{i}}-\alpha_{\mathrm{i}} \mathrm{x}_{\mathrm{i}},(\mathrm{i}=1,2,3)
$$

where, the scales $\alpha_{1}-\alpha_{3}$ are real numbers. The error dynamics is obtained as:

$$
\begin{aligned}
& \dot{e}_{1}=-p\left(e_{1}-y_{2}+\alpha_{1} x_{2}\right)+u_{1} \\
& \dot{e}_{2}=r e_{2}-y_{1} y_{3}+\alpha_{2} x_{1} x_{3}+u_{2} \\
& \dot{e}_{3}=-q e_{3}+y_{1} y_{2}-\alpha_{3} x_{1} x_{2}+u_{3}
\end{aligned}
$$
by:

Researchers consider the adaptive controller defined

$$
\begin{aligned}
& \mathrm{u}_{1}=\hat{\mathrm{p}}\left(\mathrm{e}_{1}-\mathrm{y}_{2}+\alpha_{1} \mathrm{x}_{2}\right)-\mathrm{k}_{1} \mathrm{e}_{1} \\
& \mathrm{u}_{2}=-\hat{\mathrm{r}} \mathrm{e}_{2}+\mathrm{y}_{1} \mathrm{y}_{3}-\alpha_{2} \mathrm{x}_{1} \mathrm{x}_{3}-\mathrm{k}_{2} \mathrm{e}_{2} \\
& \mathrm{u}_{3}=\hat{\mathrm{q}} \mathrm{e}_{3}-\mathrm{y}_{1} \mathrm{y}_{2}+\alpha_{3} \mathrm{x}_{1} \mathrm{x}_{2}-\mathrm{k}_{3} \mathrm{e}_{3}
\end{aligned}
$$

where, $\hat{p}-\hat{r}$ are estimates of the parameters p-r, respectively. Substituting Eq. 20 into Eq. 19, researchers obtain the closed-loop error dynamics:

$$
\begin{aligned}
& \dot{e}_{1}=-(p-\hat{p})\left(e_{1}-y_{2}+\alpha_{1} x_{2}\right)-k_{1} e_{1} \\
& \dot{e}_{2}=(r-\hat{r}) e_{2}-k_{2} e_{2} \\
& \dot{e}_{3}=-(q-\hat{q}) e_{3}-k_{3} e_{3}
\end{aligned}
$$

Researchers define the parameter estimation errors as:

$$
e_{p}=p-\hat{p}, e_{q}=q-\hat{q}, e_{r}=r-\hat{r}
$$

Using Eq. 22, the error dynamics Eq. 21 is simplified as:

$$
\begin{aligned}
& \dot{e}_{1}=-e_{p}\left(e_{1}-y_{2}+\alpha_{1} x_{2}\right)-k_{1} e_{1} \\
& \dot{e}_{2}=e_{r} e_{2}-k_{2} e_{2} \\
& \dot{e}_{3}=-e_{q} e_{3}-k_{3} e_{3}
\end{aligned}
$$

For the derivation of the update law for adjusting the estimates of parameters, the Lyapunov Method is used. Researchers consider the quadratic Lyapunov function defined by:

$$
\mathrm{V}=\frac{1}{2}\left(\mathrm{e}_{1}^{2}+\mathrm{e}_{2}^{2}+\mathrm{e}_{3}^{2}+\mathrm{e}_{\mathrm{p}}^{2}+\mathrm{e}_{\mathrm{q}}^{2}+\mathrm{e}_{\mathrm{r}}^{2}\right)
$$

which is positive definite on $\mathrm{R}^{7}$. Researchers note that:

$$
\dot{\mathrm{e}}_{\mathrm{p}}=-\mathrm{p}, \quad \dot{\mathrm{e}}_{\mathrm{q}}=-\dot{\hat{\mathrm{q}}}, \quad \dot{\mathrm{e}}_{\mathrm{r}}=-\dot{\hat{\mathrm{r}}}
$$

Differentiating Eq. 24 along the trajectories of the system 23 and using Eq. 25, researchers find that:

$$
\begin{aligned}
\dot{\mathrm{V}}= & -\mathrm{k}_{1} \mathrm{e}_{1}^{2}-\mathrm{k}_{2} \mathrm{e}_{2}^{2}-\mathrm{k}_{3} \mathrm{e}_{3}^{2}+ \\
& \mathrm{e}_{\mathrm{p}}\left[-\mathrm{e}_{1}\left(\mathrm{e}_{1}-\mathrm{y}_{2}+\alpha_{1} \mathrm{x}_{2}\right)-\dot{\hat{\mathrm{p}}}\right]+ \\
& \mathrm{e}_{\mathrm{q}}\left[-\mathrm{e}_{3}^{2}-\dot{\hat{\mathrm{q}}}\right]+\mathrm{e}_{\mathrm{r}}\left[\mathrm{e}_{2}^{2}-\dot{\hat{\mathrm{r}}}\right]
\end{aligned}
$$

In view of Eq. 26, the estimated parameters are updated by the following law:

$$
\begin{aligned}
& \dot{\hat{\mathrm{p}}}=-\mathrm{e}_{1}\left(\mathrm{e}_{1}-\mathrm{y}_{2}+\alpha_{1} \mathrm{x}_{2}\right)+\mathrm{k}_{4} \mathrm{e}_{\mathrm{p}} \\
& \dot{\hat{\mathrm{q}}}=-\mathrm{e}_{3}^{2}+\mathrm{k}_{5} \mathrm{e}_{\mathrm{q}} \\
& \dot{\hat{\mathrm{r}}}=\mathrm{e}_{2}^{2}+\mathrm{k}_{6} \mathrm{e}_{\mathrm{r}}
\end{aligned}
$$

where, the gains $\mathrm{k}_{4}-\mathrm{k}_{6}$ are positive constants.

Theorem 2: The adaptive control law Eq. 20 achieves General Projective Synchronization (GPS) between the identical Lu-Chen 2-Scroll Chaotic Systems 16 and 17 
where the parameter update law is given by Eq. 27 and the gains $\mathrm{k}_{\mathrm{i}}(\mathrm{i}=1,2, \ldots, 6)$ are positive constants. The GPS errors $\mathrm{e}_{\mathrm{i}}(\mathrm{i}=1,2,3)$ and the parameter estimation errors $e_{p}-e_{r}$ converge exponentially to zero as $t \rightarrow \infty$ for all initial conditions.

Proof: Upon substituting the parameter update law Eq. 27 into the Eq. 26, researchers obtain the derivative of the quadratic Lyapunov function $V$ as:

$$
\dot{\mathrm{V}}=-\mathrm{k}_{1} \mathrm{e}_{1}^{2}-\mathrm{k}_{2} \mathrm{e}_{2}^{2}-\mathrm{k}_{3} \mathrm{e}_{3}^{2}-\mathrm{k}_{4} \mathrm{e}_{\mathrm{p}}^{2}-\mathrm{k}_{5} \mathrm{e}_{\mathrm{q}}^{2}-\mathrm{k}_{6} \mathrm{e}_{\mathrm{r}}^{2}
$$

which is a negative definite function on $\mathrm{R}^{7}$. Hence, by Lyapunov Stability Theory (Hahn, 1967), it follows that the GPS errors $\mathrm{e}_{1} \rightarrow 0, \mathrm{e}_{2} \rightarrow 0, \mathrm{e}_{3} \rightarrow 0$ as $\mathrm{t} \rightarrow \infty$ and the parameter estimator errors $\mathrm{e}_{\mathrm{p}} \rightarrow 0, \mathrm{e}_{\mathrm{q}} \rightarrow 0, \mathrm{e}_{\mathrm{r}} \rightarrow 0$ as $\mathrm{t} \rightarrow \infty$ for all initial conditions.

Numerical results: For the numerical simulations, the fourth order Runge-Kutta Method is used to solve the two systems of differential Eq. 16 and 17 with the adaptive controller Eq. 20. The parameter estimates of the identical Lu-Chen Systems Eq. 16 and 17 are taken so that the systems exhibit 2 -scroll chaotic attractors, i.e.:

$$
p=36, q=3, r=20
$$

Researchers take the state feedback gains as:

$$
k_{1}=4 \text { for } i=1,2, \ldots, 6
$$

The initial values of the parameter estimates are chosen as:

$$
\hat{\mathrm{p}}(0)=5, \hat{\mathrm{q}}(0)=12, \hat{\mathrm{r}}(0)=16
$$

The initial values of the Master System (16) are chosen as:

$$
x_{1}(0)=22, x_{2}(0)=-8, x_{3}(0)=-6
$$

The initial values of the slave system (17) are chosen as:

$$
\mathrm{y}_{1}(0)=9, \mathrm{y}_{2}(0)=-20, \mathrm{y}_{3}(0)=2
$$

The GPS scales $\alpha_{1}$ are chosen as:

$$
\alpha_{1}=1.8, \alpha_{2}=2.7, \alpha_{3}=-1.5
$$

Figure 7 shows the GPS between the identical Lu-Chen-Cheng 4-Scroll Chaotic Systems 16 and 17. Figure 8 shows the time-history of the GPS errors $\mathrm{e}_{1}-\mathrm{e}_{3}$. Figure 9 shows that the parameter estimates p-q converge

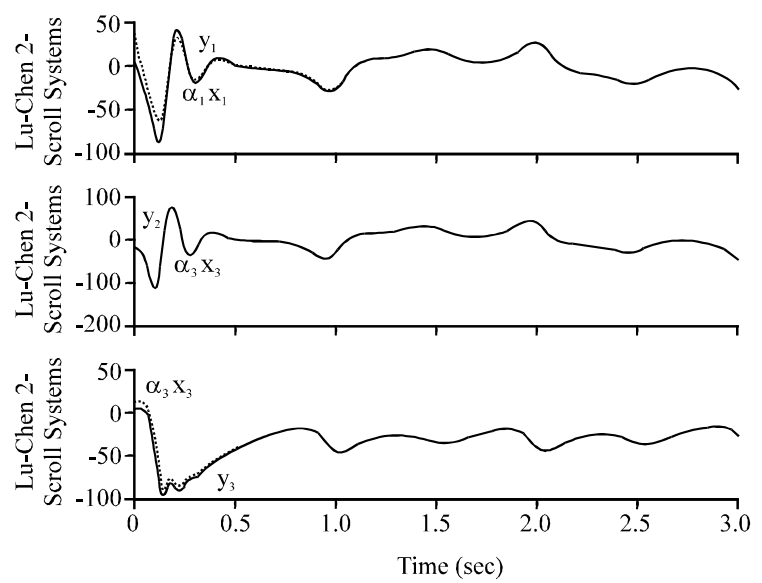

Fig. 7: GPS of the identical Lu-Chen 2-Scroll Systems

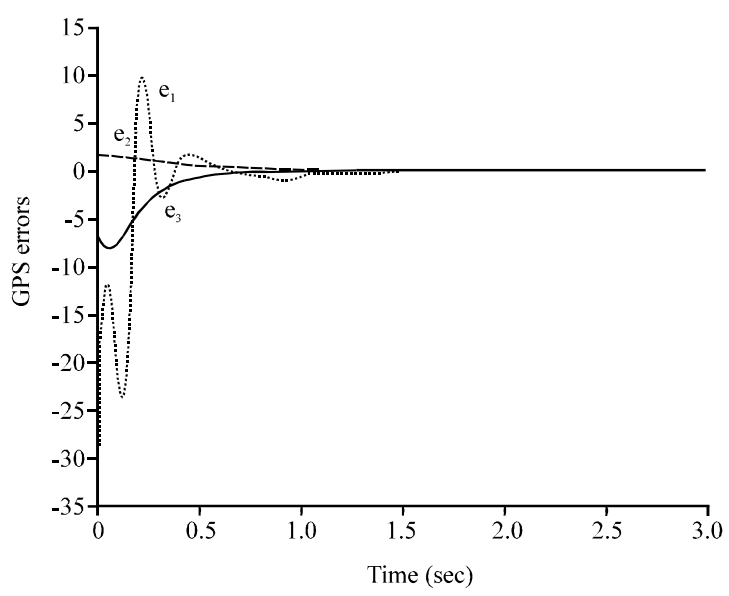

Fig. 8: Time history of the GPS errors

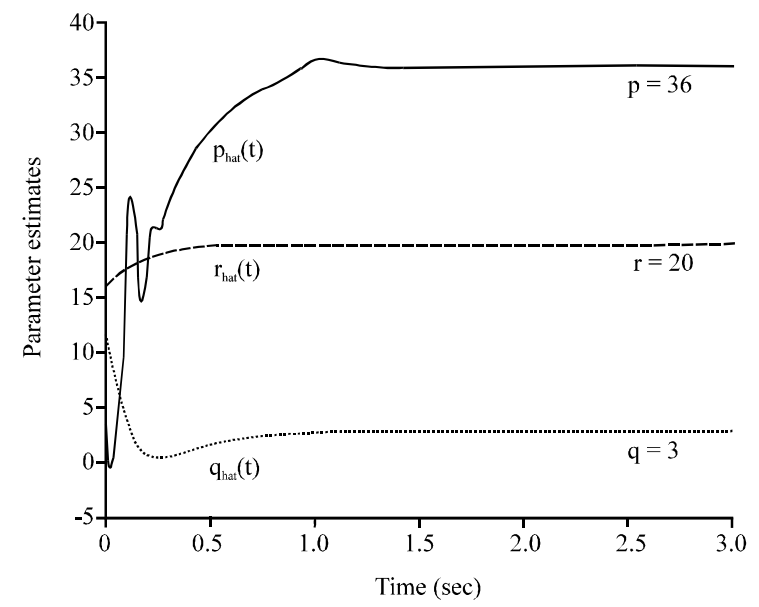

Fig. 9: Time history of the parameter estimates

to the chosen values of the system parameters $\mathrm{p}-\mathrm{q}$, respectively as $t \rightarrow \infty$. Figure 10 shows the time-history of the parameter estimation errors $\mathrm{e}_{\mathrm{p}}-\mathrm{e}_{\mathrm{r}}$. 


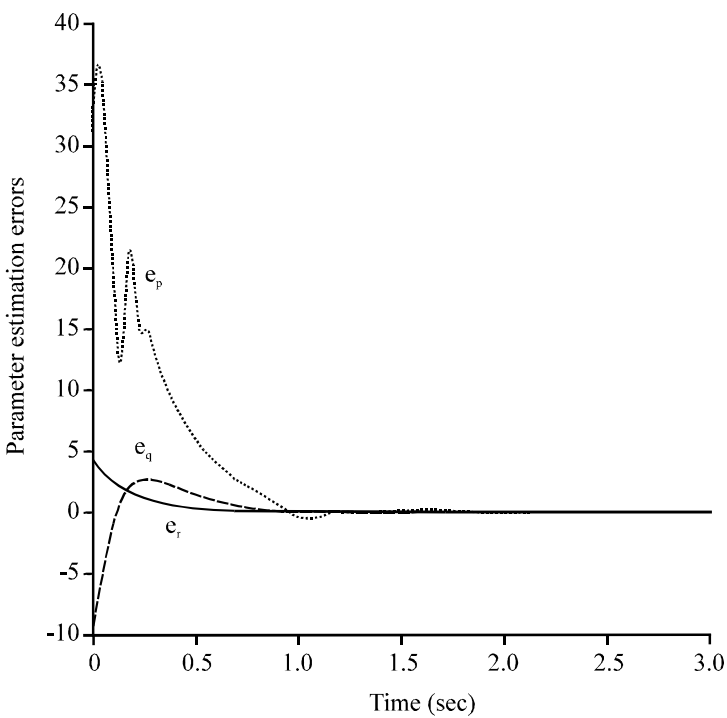

Fig. 10: Time history of the parameter estimation errors

\section{ADAPTIVE GENERALIZED PROJECTIVE SYNCHRONIZATION OF LI AND LU-CHEN 2-SCROLL SYSTEMS}

Theoretical results: In this study, researchers deploy adaptive control to derive results for the Generalized Projective Synchronization (GPS) of the non-identical Liu-Chen and Lu-Chen-Cheng 4-Scroll Systems (2004) when the system parameters are unknown. Thus, the master system is described by the Li dynamics:

$$
\begin{aligned}
& \dot{x}_{1}=a\left(x_{2}-x_{1}\right) \\
& \dot{x}_{2}=-x_{2}+x_{1} x_{3} \\
& \dot{x}_{3}=b-c x_{3}-x_{1} x_{2}
\end{aligned}
$$

Where:

$\mathrm{x}_{1}-\mathrm{x}_{3}=$ The states

$\mathrm{a}-\mathrm{c}=$ Unknown parameters of the system

Also, the Slave System is described by the controlled Lu-Chen dynamics:

$$
\begin{aligned}
& \dot{\mathrm{y}}_{1}=\mathrm{p}\left(\mathrm{y}_{2}-\mathrm{y}_{1}\right)+\mathrm{u}_{1} \\
& \dot{\mathrm{y}}_{2}=\mathrm{ry}_{2}-\mathrm{y}_{1} \mathrm{y}_{3}+\mathrm{u}_{2} \\
& \dot{\mathrm{y}}_{3}=-\mathrm{qy}_{3}+\mathrm{y}_{1} \mathrm{y}_{2}+\mathrm{u}_{3}
\end{aligned}
$$

Where:

$\mathrm{y}_{1}-\mathrm{y}_{3}=$ The states

p-r $=$ Unknown parameters of the system

$\mathrm{u}_{1}-\mathrm{u}_{3}=$ The adaptive controls to be designed

The GPS synchronization errors are defined as:

$$
\mathrm{e}_{\mathrm{i}}=\mathrm{y}_{\mathrm{i}}-\alpha_{\mathrm{i}} \mathrm{x}_{\mathrm{i}},(\mathrm{i}=1,2,3)
$$

where, the scales $\alpha_{1}-\alpha_{3}$ are real numbers. The error dynamics is obtained as:

$$
\begin{aligned}
& \dot{e}_{1}=p\left(y_{2}-y_{1}\right)-\alpha_{1}\left[a\left(x_{2}-x_{1}\right)\right]+u_{1} \\
& \dot{e}_{2}=r y_{2}-y_{1} y_{3}-\alpha_{2}\left[-x_{2}+x_{1} x_{3}\right]+u_{2} \\
& \dot{e}_{3}=-q y_{3}+y_{1} y_{2}-\alpha_{3}\left[b-c x_{3}-x_{1} x_{2}\right]+u_{3}
\end{aligned}
$$

Researchers consider the adaptive controller defined by:

$$
\begin{aligned}
& \mathrm{u}_{1}=\hat{\mathrm{p}}\left(\mathrm{y}_{2}-\mathrm{y}_{1}\right)+\alpha_{1}\left[\hat{\mathrm{a}}\left(\mathrm{x}_{2}-\mathrm{x}_{1}\right)\right]-\mathrm{k}_{1} \mathrm{e}_{1} \\
& \mathrm{u}_{2}=\hat{\mathrm{r}} \mathrm{y}_{2}+\mathrm{y}_{1} \mathrm{y}_{3}+\alpha_{2}\left[-\mathrm{x}_{2}+\mathrm{x}_{1} \mathrm{x}_{3}\right]-\mathrm{k}_{2} \mathrm{e}_{2} \\
& \mathrm{u}_{3}=\hat{\mathrm{q}} \mathrm{y}_{3}-\mathrm{y}_{1} \mathrm{y}_{2}+\alpha_{3}\left[\hat{\mathrm{b}}-\hat{\mathrm{c}} \mathrm{x}_{3}-\mathrm{x}_{1} \mathrm{x}_{2}\right]-\mathrm{k}_{3} \mathrm{e}_{3}
\end{aligned}
$$

where, $\hat{a}, \hat{b}, \hat{c}, \hat{p}, \hat{\mathrm{q}}, \hat{\mathrm{r}}$ are estimates of the parameters $\mathrm{a}$, b, c, p, q, r, respectively. Substituting Eq. 33 into Eq. 32, researchers obtain the closed-loop error dynamics:

$$
\begin{aligned}
& \dot{\mathrm{e}}_{1}=(\mathrm{p}-\hat{\mathrm{p}})\left(\mathrm{y}_{2}-\mathrm{y}_{1}\right)-\alpha_{1}(\mathrm{a}-\hat{\mathrm{a}})\left(\mathrm{x}_{2}-\mathrm{x}_{1}\right)-\mathrm{k}_{1} \mathrm{e}_{1} \\
& \dot{\mathrm{e}}_{2}=(\mathrm{r}-\hat{\mathrm{r}}) \mathrm{y}_{2}-\mathrm{k}_{2} \mathrm{e}_{2} \\
& \dot{\mathrm{e}}_{3}=-(\mathrm{q}-\hat{\mathrm{q}}) \mathrm{y}_{3}-\alpha_{3}(\mathrm{~b}-\hat{\mathrm{b}})+\alpha_{3} \mathrm{x}_{3}(\mathrm{c}-\hat{\mathrm{c}})-\mathrm{k}_{3} \mathrm{e}_{3}
\end{aligned}
$$

Researchers define the parameter estimation errors as :

$$
\begin{aligned}
& \mathrm{e}_{\mathrm{a}}=\mathrm{a}-\hat{\mathrm{a}}, \mathrm{e}_{\mathrm{b}}=\mathrm{b}-\hat{\mathrm{b}} \\
& \mathrm{e}_{\mathrm{c}}=\mathrm{c}-\hat{\mathrm{c}}, \mathrm{e}_{\mathrm{p}}=\mathrm{p}-\hat{\mathrm{p}} \\
& \mathrm{e}_{\mathrm{q}}=\mathrm{q}-\hat{\mathrm{q}}, \mathrm{e}_{\mathrm{r}}=\mathrm{r}-\hat{\mathrm{r}}
\end{aligned}
$$

Using Eq. 35, the error dynamics Eq. 34 is simplified as:

$$
\begin{aligned}
& \dot{e}_{1}=e_{p}\left(y_{2}-y_{1}\right)-\alpha_{1} e_{a}\left(x_{2}-x_{1}\right)-k_{1} e_{1} \\
& \dot{e}_{2}=e_{r} y_{2}-k_{2} e_{2} \\
& \dot{e}_{3}=-e_{q} y_{3}-\alpha_{3} e_{b}+\alpha_{3} x_{3} e_{c}-k_{3} e_{3}
\end{aligned}
$$

For the derivation of the update law for adjusting the estimates of parameters, the Lyapunov Method is used. Researchers consider the quadratic Lyapunov function defined by:

$$
\mathrm{V}=\frac{1}{2}\left[\mathrm{e}_{1}^{2}+\mathrm{e}_{2}^{2}+\mathrm{e}_{3}^{2}+\mathrm{e}_{\mathrm{a}}^{2}+\mathrm{e}_{\mathrm{b}}^{2}+\mathrm{e}_{\mathrm{c}}^{2}+\mathrm{e}_{\mathrm{p}}^{2}+\mathrm{e}_{\mathrm{q}}^{2}+\mathrm{e}_{\mathrm{r}}^{2}\right]
$$

which is positive definite on $\mathrm{R}^{9}$. Researchers note that:

$$
\begin{aligned}
& \dot{\mathrm{e}}_{\mathrm{a}}=-\dot{\hat{\mathrm{a}}}, \dot{\mathrm{e}}_{\mathrm{b}}=-\dot{\hat{\mathrm{b}}}, \dot{\mathrm{e}}_{\mathrm{c}}=-\dot{\hat{\mathrm{c}}} \\
& \dot{\mathrm{e}}_{\mathrm{p}}=-\dot{\hat{\mathrm{p}}}, \dot{\mathrm{e}}_{\mathrm{q}}=-\dot{\hat{\mathrm{q}}}, \dot{\mathrm{e}}_{\mathrm{r}}=-\dot{\hat{\mathrm{r}}}
\end{aligned}
$$


Differentiating Eq. 37 along the trajectories of the system 36 and using Eq. 38, researchers find that:

$$
\begin{aligned}
\dot{\mathrm{V}}= & -\mathrm{k}_{1} \mathrm{e}_{1}^{2}-\mathrm{k}_{2} \mathrm{e}_{2}^{2}-\mathrm{k}_{3} \mathrm{e}_{3}^{2}+\mathrm{e}_{\mathrm{a}}\left[-\alpha_{1} \mathrm{e}_{1}\left(\mathrm{x}_{2}-\mathrm{x}_{1}\right)-\dot{\hat{\mathrm{a}}}\right]+ \\
& \mathrm{e}_{\mathrm{b}}\left[-\alpha_{3} \mathrm{e}_{3}-\dot{\hat{b}}\right]+\mathrm{e}_{\mathrm{c}}\left[\alpha_{3} \mathrm{x}_{3} \mathrm{e}_{3}-\dot{\hat{\mathrm{c}}}\right]+ \\
& \mathrm{e}_{\mathrm{p}}\left[\mathrm{e}_{1}\left(\mathrm{y}_{2}-\mathrm{y}_{1}\right)-\hat{\hat{\mathrm{p}}}\right]+\mathrm{e}_{\mathrm{q}}\left[-\mathrm{y}_{3} \mathrm{e}_{3}-\dot{\hat{\mathrm{q}}}\right]+\mathrm{e}_{\mathrm{r}}\left[\mathrm{y}_{2} \mathrm{e}_{2}-\hat{\hat{\mathrm{r}}}\right]
\end{aligned}
$$

In view of Eq. 39, the estimated parameters are updated by the following law:

$$
\begin{aligned}
& \dot{\hat{\mathrm{a}}}=-\alpha_{1} \mathrm{e}_{1}\left(\mathrm{x}_{2}-\mathrm{x}_{1}\right)+\mathrm{k}_{4} \mathrm{e}_{\mathrm{a}}, \dot{\hat{\mathrm{b}}}=-\alpha_{3} \mathrm{e}_{3}+\mathrm{k}_{5} \mathrm{e}_{\mathrm{b}} \\
& \dot{\hat{\mathrm{c}}}=\alpha_{3} \mathrm{x}_{3} \mathrm{e}_{3}+\mathrm{k}_{6} \mathrm{e}_{\mathrm{c}}, \quad \dot{\hat{\mathrm{p}}}=\mathrm{e}_{1}\left(\mathrm{y}_{2}-\mathrm{y}_{1}\right)+\mathrm{k}_{7} \mathrm{e}_{\mathrm{p}} \\
& \dot{\hat{\mathrm{q}}}=-\mathrm{y}_{3} \mathrm{e}_{3}+\mathrm{k}_{8} \mathrm{e}_{\mathrm{q}}, \quad \dot{\hat{\mathrm{r}}}=\mathrm{y}_{2} \mathrm{e}_{2}+\mathrm{k}_{9} \mathrm{e}_{\mathrm{r}}
\end{aligned}
$$

where the gains $\mathrm{k}_{\mathrm{i}}(\mathrm{i}=4, \ldots, 9)$ are positive constants.

Theorem 3: The adaptive control law (33) achieves General Projective Synchronization (GPS) between the non-identical Li 2-Scroll System 29 and the Lu-Chen 2-Scroll Chaotic System 30 where the parameter update law is given by 40 and the gains $k_{i},(i=1,2, \ldots, 10)$ are positive constants. The GPS errors $e_{i},(i=1,2,3)$ and the parameter estimation errors $e_{a}, e_{b}, e_{c}, e_{p}, e_{q}, e_{r}$, converge exponentially to zero as $\mathrm{t} \rightarrow \infty$ for all initial conditions.

Proof: Upon substituting the parameter update law 40 into the Eq. 39, researchers obtain the derivative of the quadratic Lyapunov function $\mathrm{V}$ as:

$$
\begin{aligned}
\dot{\mathrm{V}}= & -\mathrm{k}_{1} \mathrm{e}_{1}^{2}-\mathrm{k}_{2} \mathrm{e}_{2}^{2}-\mathrm{k}_{3} \mathrm{e}_{3}^{2}-\mathrm{k}_{4} \mathrm{e}_{\mathrm{a}}^{2}-\mathrm{k}_{5} \mathrm{e}_{\mathrm{b}}^{2}- \\
& \mathrm{k}_{6} \mathrm{e}_{\mathrm{c}}^{2}-\mathrm{k}_{7} \mathrm{e}_{\mathrm{p}}^{2}-\mathrm{k}_{8} \mathrm{e}_{\mathrm{q}}^{2}-\mathrm{k}_{9} \mathrm{e}_{\mathrm{r}}^{2}
\end{aligned}
$$

which is a negative definite function on $\mathrm{R}^{9}$. Hence, by Lyapunov Stability Theory (Hahn, 1967) it follows that the GPS errors $\mathrm{e}_{1} \rightarrow 0, \mathrm{e}_{2} \rightarrow 0, \mathrm{e}_{3} \rightarrow 0$ as $\mathrm{t} \rightarrow \infty$ and the parameter estimator errors $\mathrm{e}_{\mathrm{a}} \rightarrow 0, \mathrm{e}_{\mathrm{b}} \rightarrow 0, \mathrm{e}_{\mathrm{b}} \rightarrow 0, \mathrm{e}_{\mathrm{p}} \rightarrow 0, \mathrm{e}_{\mathrm{q}} \rightarrow$ $0, \mathrm{e}_{\mathrm{r}} \rightarrow 0$ as $\mathrm{t} \rightarrow \infty$ for all initial conditions

Numerical results: For the numerical simulations, the fourth order Runge-Kutta Method is used to solve the two systems of differential Eq. 29 and 30 with the adaptive controller 33. The parameter estimates of the non-identical Li System 29 and the Lu-Chen System 30 are chosen so that the systems exhibit 2-scroll chaotic attractors, i.e.:

$$
a=5, b=16, c=1, p=36, q=3, r=20
$$

Researchers take the state feedback gains as:

$$
\mathrm{k}_{1}=4 \text { for } \mathrm{i}=1,2, \ldots, 9
$$

The initial values of the parameter estimates are chosen as:

$$
\hat{\mathrm{a}}(0)=8, \hat{\mathrm{b}}(0)=12, \hat{\mathrm{c}}(0)=5, \hat{\mathrm{p}}(0)=4, \hat{\mathrm{q}}(0)=24, \hat{\mathrm{r}}(0)=19
$$

The initial values of the Master System (29) are chosen as:

$$
x_{1}(0)=26, x_{2}(0)=12, x_{3}=-8
$$

The initial values of the Slave System (30) are chosen as:

$$
y_{1}(0)=12, y_{2}(0)=-14, y_{3}(0)=-5
$$

The GPS scales $\alpha_{1}$ are chosen as:

$$
\alpha_{1}=1.2, \alpha_{2}=-2.3, \alpha_{3}=-0.8
$$

Figure 11 shows the GPS between the Li and Lu-Chen 2-Scroll Chaotic Systems. Figure 12 shows the time-history of the GPS errors $\mathrm{e}_{1}-\mathrm{e}_{3}$. Figure 13 shows that the parameter estimates $\hat{a}-\hat{c}$ converge to the chosen values of the system parameters a-c, respectively as $t \rightarrow \infty$. Figure 14 shows the time-history of the parameter estimation errors $\mathrm{e}_{\mathrm{a}}-\mathrm{e}_{\mathrm{c}}$.

Figure 15 shows that the parameter estimates $\hat{\mathrm{p}}-\hat{\mathrm{r}}$ converge to the chosen values of the system parameters $p-q$, respectively as $t \rightarrow \infty$. Figure 16 shows the time-history of the parameter estimation errors $\mathrm{e}_{\mathrm{p}}-\mathrm{e}_{\mathrm{r}}$.

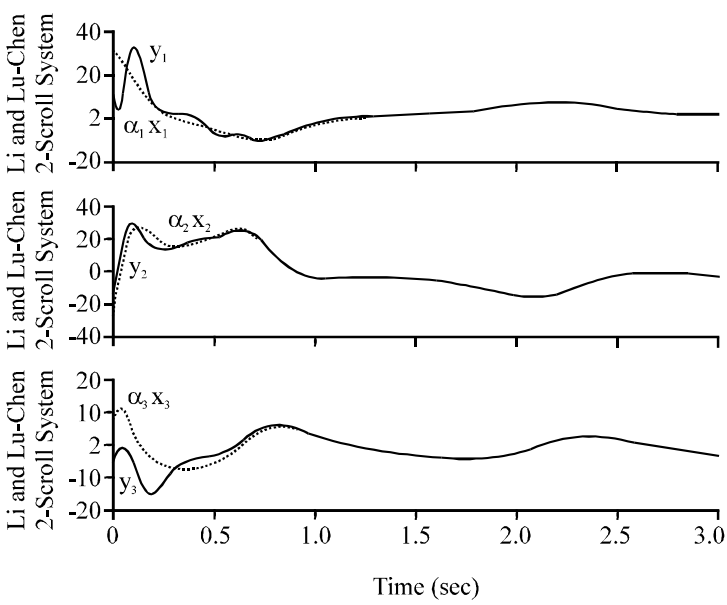

Fig. 11: GPS of the Li and Lu-Chen 2 
Int. J. Soft Comput., 7 (4): 146-156, 2012
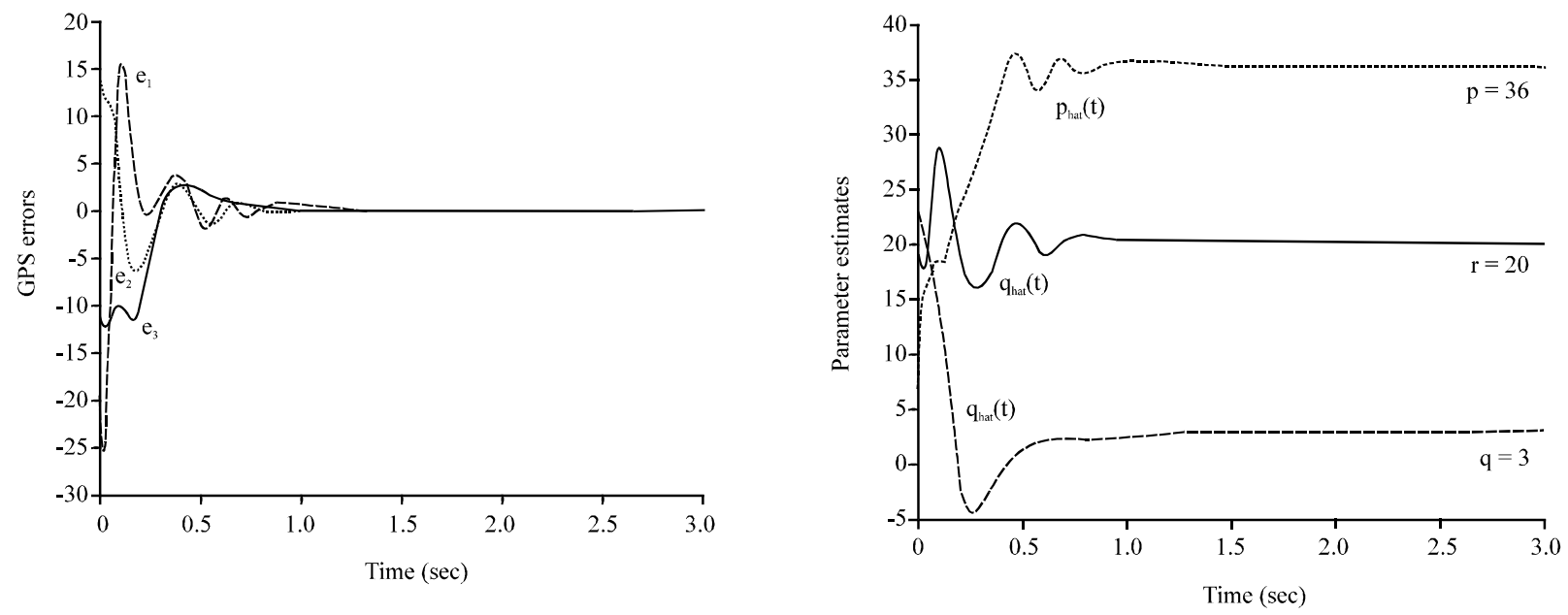

Fig. 12: Time history of the GPS errors $\mathrm{e}_{1}-\mathrm{e}_{3}$

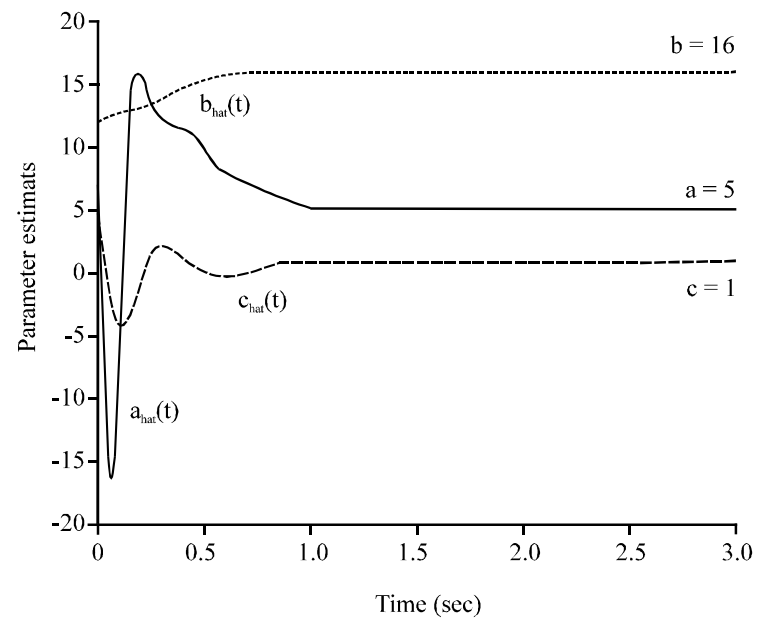

Fig. 13: Time history of the parameter estimates $\hat{a}-\hat{c}$

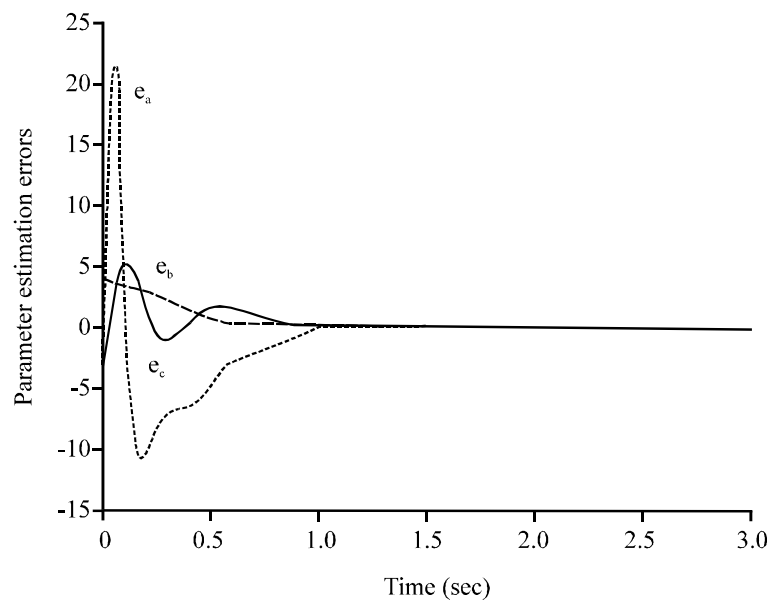

Fig. 14: Time history of the parameter estimation errors $\mathrm{e}_{\mathrm{a}}-\mathrm{e}_{\mathrm{c}}$

Fig. 15: Time history of the parameter estimates $\mathrm{e}_{\mathrm{a}}-\mathrm{e}_{\mathrm{c}}$

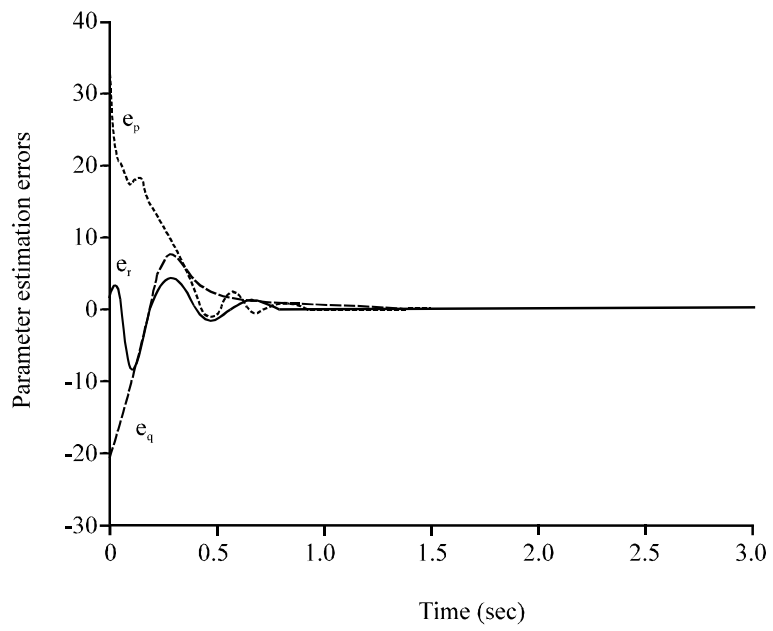

Fig. 16: Time history of the parameter estimation errors $\mathrm{e}_{\mathrm{p}}-\mathrm{e}_{\mathrm{r}}$

\section{CONCLUSION}

In this study, researchers have designed adaptive controllers for achieving Generalized Projective Synchronization (GPS) of 2-scroll chaotic attractors, viz. the identical Li 2-Scroll Chaotic Systems (2009), the identical Lu-Chen 2-Scroll Chaotic Systems (2002) and the non-identical Li and Lu-Chen 2-Scroll Chaotic Systems when the system parameters are unknown. The adaptive GPS synchronization results for the 2-Scroll Chaotic Systems have been proved using the Lyapunov Stability Theory. Numerical simulations have been presented to validate and demonstrate the effectiveness of the GPS synchronization results derived in this study. 


\section{REFERENCES}

Alligood, K.T., T. Sauer and J.A. Yorke, 1997. An Introduction to Dynamical Systems. Springer, New York, USA.

Blasius, B., A. Huppert and L. Stone, 1999. Complex dynamics and phase synchronization in spatially extended ecological system. Nature, 399: 354-359.

Chen, H.K., 2005. Global chaos synchronization of new chaotic systems via nonlinear control. Chaos Solitons Fractals, 23: 1245-1251.

Chen, S. and J. Lu, 2002. Synchronization of an uncertain unified system via adaptive control. Chaos Solitons Fractals, 14: 643-647.

Chiang, T., J. Lin, T. Liao and J. Yan, 2008. Antisynchronization of uncertain unified chaotic systems with dead-zone nonlinearity. Nonlinear Anal., 68: 2629-2637.

Cuomo, K.M. and A.V. Oppenheim, 1993. Circuit implementation of synchronized chaos with applications to communications. Phys. Rev. Lett., 71: 65-68.

Hahn, W., 1967. The Stability of Motion. Springer-Verlag, Berlin.

Han, S.K., C. Kerrer and Y. Kuramoto, 1995. Dephasing and bursting in coupled neural oscillators. Phys. Rev. Lett., 75: 3190-3193.

Ho, M.C. and Y.C. Hung, 2002. Synchronization of two different chaotic systems using generalized active control. Phys. Lett. A, 301: 424-428.

Huang, L., R. Feng and M. Wang, 2004. Synchronization of chaotic systems via nonlinear control. Phys. Lett. A, 320: 271-275.

Jia, Q., 2007. Projective synchronization of a new hyperchaotic lorenz system. Phys. Lett. A, 370: 40-45.

Kocarev, L. and U. Parlitz, 1995. General approach for chaotic synchronization with application to communication. Phys. Rev. Lett., 74: 5028-5031.

Lakshmanan, M. and K. Murali, 1996. Chaos in Nonlinear Oscillators: Controlling and Synchronization. World Scientific, Singapore.

Lee, S.H., V. Kapila, M. Porfiri and A. Panda, 2010. Master-slave synchronization of continuously and intermittently coupled sampled-data chaotic oscillators. Commun. Nonlinear Sci. Numer. Simul., 15: 4100-4113.

Li, X., 2009. Generalized projective synchronization using nonlinear control method. Int. J. Nonlinear Sci., 8: 79-85.

Li, X.F., K.E. Chlouverakis and D.L. Xu, 2009. Nonlinear dynamics and circuit realization of a new chaotic flow: A variant of Lorenz, Chen and Lu. Nonlinear Anal., 10: 2357-2368.
Lu, J. and G. Chen, 2002. A new chaotic attractor coined. Int. J. Bifurcation Chaos, 12: 659-661.

Lu, J., X. Wu, X. Han and J. Lu, 2004. Adaptive feedback synchronization of a unified chaotic system. Phys. Lett. A, 329: 327-333.

Murali, K. and M. Lakshmanan, 2003. Secure communication using a compound signal using sampled-data feedback. Applied Math. Mech., 11: 1309-1315.

Ott, E., C. Grebogi and J.A. Yorke, 1990. Controlling chaos. Phys. Rev. Lett., 64: 1196-1199.

Park, J.H. and O.M. Kwon, 2003. A novel criterion for delayed feedback control of time-delay chaotic systems. Chaos Solitons Fractals, 17: 709-716.

Park, J.H., 2006. Synchronization of Genesio chaotic system via backstepping approach. Chaos Solitons Fractals, 27: 1369-1375.

Pecora, L.M. and T.L. Carroll, 1990. Synchronization in chaotic systems. Phys. Rev. Lett., 64: 821-824.

Sarasu, P. and V. Sundarapandian, 2011a. Active controller design for generalized projective synchronization of four-scroll chaotic systems. Int. J. Syst. Signal Control Engin. Appli., 4: 26-33.

Sarasu, P. and V. Sundarapandian, 2011b. Generalized projective synchronization of hyperchaotic Lorenz and hyperchaotic Qi systems via nonlinear control. Int. J. Soft Comput., 6: 216-223.

Sarasu, P. and V. Sundarapandian, 2012. Active controller design for the generalized projective synchronization of 3-scroll chaotic systems. Int. J. Adv. Inform. Technol., 2: 37-53.

Slotine, J.E. and S.S. Sastry, 1983. Tracking control of non-linear systems using sliding surface with application to robotic manipulators. Int. J. Control, 38: 465-492.

Sundarapandian, V., 2011a. Adaptive control and synchronization of uncertain Liu-Chen-Liu system. Int. J. Comput. Inform. Syst., 3: 1-6.

Sundarapandian, V., 2011b. Hybrid synchronization of hyperchaotic rossler and hyperchaotic lorenz systems by active control. Int. J. Adv. Sci. Technol., 2: $1-10$.

Sundarapandian, V., 2011c. Hybrid synchronization of T and Cai systems by active nonlinear control. Int. J. Control Theory Applic., 4: 1-10.

Sundarapandian, V., 2011d. Adaptive control and synchronization of the Shaw chaotic system. Int. J. Found. Comput. Sci. Technol., 1: 1-11.

Sundarapandian, V., 2011e. Hybrid synchronization of Harb and Wang chaotic systems by nonlinear control. Int. J. Comput. Inform. Syst., 3: 7-12. 
Sundarapandian, V., 2011f. Hybrid synchronization of Lorenz and Pehlivan systems by active nonlinear control. Int. J. Adv. Sci. Technol., 2: 10-20.

Sundarapandian, V., 2011g. Anti-synchronization of Arneodo and Coullet systems by active nonlinear control. Int. J. Control Theory Applied, 4: 25-36.

Sundarapandian, V., $2011 \mathrm{~h}$. Global chaos synchronization of arneodo and shimizu-morioka chaotic systems by active nonlinear control. Int. J. Adv. Sci. Technol., 2: $32-42$.

Utkin, V.I., 1993. Sliding mode control design principles and applications to electric drives. IEEE Trans. Ind. Electron., 40: 23-36.

Vaidyanathan, S. and S. Sampath, 2011. Sliding mode controller design for global chaos synchronization of hyperchaotic Lorenz systems. Comput. Sci. Eng.: Int. J., 1: 61-70.
Vincent, U.E., 2007. Controlling directed transport in inertia ratchets via adaptive backstepping control. Acta Phys. Pol. B, 38: 2459-2469.

Wang, C. and S.S. Ge, 2001. Adaptive synchronization of uncertain chaotic systems via backstepping design. Chaos, Solitons Fractals, 12: 1199-1206.

Wang, Y.W. and Z.H. Guan, 2006. Generalized synchronization of continuous chaotic systems. Chaos Solitons Fractals, 27: 97-101.

Xiau-Qun, W. and L. Jun-An, 2003. Parameter identification and backstepping control of uncertain system. Chaos, Solitons Fractals, 18: 721-729.

Zhang, $\mathrm{X}$. and H. Zhu, 2008. Anti-synchronization of two different hyperchaotic systems via active and adaptive control. Int. J. Nonlinear Sci., 6: 216-223. 